\title{
Housing Tenure Choice and Housing Expenditures in the Czech Republic
}

\author{
Dagmar Špalková ${ }^{1} \&$ Jiří Špalek ${ }^{1}$ \\ ${ }^{1}$ Faculty of Economics and Administration, Masaryk University, Brno, Czech Republic \\ Correspondence: Jiř́ Špalek, Faculty of Economics and Administration, Masaryk University, Lipová 41a, Brno \\ 60200, Czech Republic. Tel: 420-549-498-008. E-mail: spalek@econ.muni.cz
}

\author{
Received: November 11, 2013 Accepted: December 17, 2013 Online Published: January 16, 2014 \\ doi:10.5539/res.v6n1p23 URL: http://dx.doi.org/10.5539/res.v6n1p23
}

\begin{abstract}
Choosing between rented housing and homeownership, the so called housing tenure choice, is a key decision made by each household. Therefore housing economists often seek an answer to the question which factors have an impact on this decision. The paper investigates potential tenure choice determinants using probit regression model based on the sample data. Results of the analysis, making use of the investigation of EU-SILC in the CR, showed that tenure choice is affected by the factors similar to those in other countries - household income, marital status of the household head and household size (persons per household). By contrast, the influence of other demographic characteristics, such as gender and age of head of the household has not been confirmed. The econometric model has also made it possible to evaluate potential impact of these factors on housing related expenses of households. In addition to the logical influence of household income, tenure choice decisions are significantly influenced by household size and residence in Prague, particularly in the rented housing sector.
\end{abstract}

Keywords: choice, determinants, expenditures, housing, tenure

\section{Introduction}

The quality of family life is affected by the place where the family lives, its location, its adequate floor area enabling sufficient privacy for the household members and many other aspects. That is why one of the key decisions made by any household is the choice between owning and renting their home, which is known in specialized literature as tenure choice.

This issue has drawn the attention of researchers for many years. They focus mostly on identifying the determinants which are relevant to the decision of households to own or rent their housing as well as on establishing the degree of their impact. A host of authors view tenure choice as an independent decision. Nevertheless, a more common opinion has it that the choice of home type is only one part of all the other decisions households have to make in relation to consumption and investment (Turner \& O'Neal, 1986). Thus tenure choice is typically analysed in connection with household mobility, housing attributes (dwelling characteristics), household attributes or as an element of consumption and investment decisions.

Our paper has combined two of the above mentioned approaches towards the exploration of tenure choice housing and household attributes. Based on the results of the probit regression model, we have defined the factors that affect tenure choice of Czech households over the period 2005-2011. Using the acquired factors we have further quantified their impact on the share of housing-related expenditures. Our aim is to establish which demographic and socioeconomic factors determine housing expenditures and the weight of their impact. To our knowledge this is the first analysis of tenure choice trends with connection to housing expenditures in the Czech Republic.

The first researcher deemed to have dealt with tenure choice in the context of household decisions on mobility was Boehm (1981). He applied a working assumption that households decide simultaneously about their housing and expected mobility and developed his own tenure choice model. He demonstrated a strong interdependence of the two decisions and he also proved that the decisions are affected by identical factors. His work was continued by other researchers such as Krumm (1984, p. 260), who criticized Boehm's approach claiming that "this approach is incomplete, because of the sample itself is likely to be determined by some of the same variables that are used to estimate the tenure status and migration decision“. Krumm developed a model by integrating the 
tenure choice model and the residential mobility decision model and tested the mutual relationship of individual decisions. It failed to confirm the independence of the decision to move and of the tenure status (the result of the choice of tenure). On the contrary it was demonstrated (as in Boehm's case) that tenure status can sometimes play an important role in the decision to move house.

Kan (2000) has some reservations about Boehm's approach as he raises objections to drawbacks related to using panel data, "the data are not fully exploited to control for unobserved heterogeneity ...". The next shortcoming is seen in the fact that "only recent movers are selected for the sample“. His analyses, based on previous studies, are made more dynamic by investigating only the households that moved house. Kan demonstrated the interdependence of moving house and choice of home ownership. At the same time he warned about overestimating the influence of socio-economic characteristics of households if we analyze only the households that have moved house.

It was Boehm (1982) who concentrated on the issue of mutual links between tenure choice and the so-called "housing attributes". More specifically, the author studied the links between tenure choice (owning or renting) and other household's requirements, such as the quality and size of the house. Boehm suggests that existing tenure choice analysis does not include all aspects of a family's housing choice. In addition to the choice between owning and renting, households have to solve other aspects too, e.g. home size, its location, availability of services, etc.

For this purpose, the author made a three-level hierarchic model. 1. A household decides about the type of housing [tenure choice: own/rent]. 2. A household makes a decision about the size of home (large or small). 3. A decision about location is made (neighborhood: high income/low income). At each level of hierarchy the choice of a specific housing characteristic is estimated as based on the previous choice made, brought to a higher level. By combining all of the probabilities, Boehm acquired eight possible housing choices. At the same time he studied the impact of selected variables, which could affect the decision-making at particular levels of the model. They include headings such as Family Size, Age of Head, Marital Status, Permanent Income, Wealth, Prior House Value, Race, Relative Price Variables etc.

The general assumption, that a household is more likely to choose a larger size and higher quality housing because of its increasing income, was confirmed. It was pointed out, however, that this assumption is met with a dependence on certain household characteristics - e.g. the household with a higher number of members seeks a larger size of housing but not necessarily a home of higher quality. In other words: "increasing income should have a strong positive impact on the probability of owning “... but ..."not all ownership categories are positively affected by increases in income, nor are all rental categories negatively affected"(Boehm, 1982, p.29). Analyses of the roles of other variables in the decision-making of households demonstrated (in accordance with the above statements) that their impact can significantly differ depending on the household character. It is one of the reasons why he considered his model as an excellent analytical tool that could help politicians find an appropriate instrument for attaining the selected aims.

An alternative approach was adopted by Andersen (2009), who assessed household preferences for housing quality using a questionnaire survey. The author divided the housing characteristics into four groups: the dwelling itself (size and number of rooms, home amenities, house type, yard or garden, view, air pollution, light, noise), its surroundings (exterior of other houses and streets, environment - green spaces, criminality, social environment), social infrastructure, (shops, restaurants, cultural facilities, sports facilities), location and transport (distance to work/school, transport accessibility, urbanization). He concluded that tenure choice is greatly affected by such factors as environment without crime and good access to public transport suitable for bringing up children. However, the survey results have to be interpreted with caution, because some of the preferences may not be realistic or feasible and they can be rather biased by each household's current housing situation.

Tenure choice is probably most frequently examined in connection with household attributes. A wide range of these characteristics can be categorized into two basic groups, namely socio - economic and demographic characteristics. Burgess (1982) added one more group, namely location factors. In his work he analyses impacts of all these determinants on tenure choice of households and also poses a question on whether the impact of individual variables differs depending on the gender of the household head. However, his attention was not on a traditional household (married couples), but in keeping with current social trends, he focused on the households headed by a single man or a single woman. According to Burgess, the probability of living in one's owned home is significantly influenced by the head's age, household size and current income in both types of households (male headed/female headed). A statistically significant but negative impact has been confirmed in case of welfare income and living within the city centre. Second income and employment status proved to have no 
influence.

Bazyl (2009) was also involved in analysing the impact of the above factors on tenure choice. She labelled them socio-demographic characteristics of households and compared their importance across several European countries. Performed analyses led her to a conclusion that marriage proved to be an important factor influencing the decision to buy a home in all analysed countries without exception. In most countries the fact that the household head is a citizen of that country (i.e. they are not foreigners) can be even more significant than the marriage itself. In most countries the odds of homeownership grows with higher age of the household head and his/her income. Bazyl gradually expanded her basic model - in the second one she included a type of location, i.e. whether a household is urban (living in the city) or rural (living in the country). Findings showed that homeownership is more likely in the countryside. In the third model, the author included only renters living in houses owned privately. The fourth model investigated only recent movers. This last case demonstrated that the impact of income on tenure choice is many times greater than the model involving all households.

An alternative approach is developed by Coolen et al. (2002). In their paper they deal with the impact of life goals and values of households on their preferences for a given housing type. Using the means-end model they proved that about $91 \%$ of decisions made about a type of housing are influenced by particular household characteristics, such as age, income, household composition etc.

Only about $9 \%$ of decisions depend on life goals and of the values of family members as for e.g. a harmonic family life or respect (status). The low percentage is accounted for by the heterogeneous nature of the answers some households formulated their answers at a very general or rather philosophical level in contrast with the decisive answers of other households.

Despite many differences in the conducted analyses, all the researchers (studying tenure choice in connection with household attributes agreed that the level of income has the most profound impact on the outcome of household decisions (In addition to above mentioned papers, the importance of income mentions also Bramley, 2011).

The fourth approach emphasizes two important aspects of ownership - consumption and investment - that must be taken into consideration in connection with the decisions about tenure choice. Home acquisition is one of most significant and largest investments for most families and as a rule the only financial resources that are available are from household income. While making their decision on whether to own or rent, households virtually decide about their portfolio composition and their present and future consumption at the same time. Artle and Varaiya (1978) were two of the first to come to this conclusion. They claimed that households make their decisions about consumption and investment so that both sides can be balanced in the course of the entire family life-cycle, which had not been taken into consideration in the existing literature. Thus home acquisition affects not only the current household consumption but also future consumption. However, according to Henderson and Ioannidis (1983), Artle and Varaiya work with unrealistic assumptions. They assumed that consumption of housing does not differ, and so households consume equally, regardless of their wealth, housing price or income. Henderson and Ioannidis (1983) attempted to mitigate these unusually restrictive assumptions but they feared that it might affect the model's feasibility.

Ulker (2008) claimed that surprisingly, little attention had been given to the impact of individual characteristics on a household's housing expenditures, although a host of authors studied a mutual relationship of these characteristics and of the decisions of households about consumption and investment. In such a manner Ulker continued to research the issues of tenure choice and developed them further. His analysis consists of two parts, the first being "estimates of the housing tenure choice "where he attempted to prove the impact of selected characteristics of households on their decisions. Ulker proved that housing tenure was linked with key life events such as marriage, labour market entry etc. as well as with the individual household characteristics such as education. Home ownership is more likely to be chosen by a household headed by a married white man in his fifties with higher education. The second part "estimates the relationship between household composition and housing expenditures“. In his view, housing expenditures for homeowners are relatively less significant in proportion to the total budget of the household, if the number of its working members goes up. Alternatively, renters (who have lower mobility costs) can be more flexible in adapting housing to their needs. As a result, their expenditures on housing and on other goods are proportionally allocated. Furthermore, the budget share of housing expenditures for renters is sensitive to changes in household composition in terms of age and gender, even if no such sensitiveness (the household size being constant) has been detected in the case of homeowners.

Tenure choice is mostly analyzed from the microeconomic perspective, since it examines individual decision-making of households depending on various factors shown above. Nevertheless, the mutual proportion 
of homeownership and renting are also influenced by other factors such as inflation, taxes, rate of unemployment, interest rates or credit availability. Influence of these macroeconomic determinants was studied by e.g. Fischer \& Jaffe (2003). According their analyses GDP has a positive but statistically insignificant impact on homeownership rate. The effect of inflation remains unproven. They did not restrict their research to the above factors only. Their ambition was to "seek to evaluate the potential impacts of social, political, legal, cultural and other variables" in order to understand "homeownership as an international phenomenon. "They concluded that they had found some factors associated with homeownership rates but they failed to develop a single equation model with the comprehensive explanatory power of homeownership as a global pattern" (Fischer \& Jaffe, 2003:37).

The issues of tenure choice were touched on by Czech authors as well. Lux and Sunega (2012) assessed the influence of the form of ownership (i.e. only tenure) on mobility. Using family accounts statistics, Tsharakyan and Zemčík (2011) studied whether the rent deregulation had an impact on households renting behaviour or their ownership status (renters vs. owners) Other case study touching rent deregulation process in the Czech Republic can be found in Jahoda, Špalková (2012). Impact of public policy on housing in Czech context is analyzed by Jahoda Godarová (2013). None of the above papers is devoted to the analysis of tenure choice itself.

The Czech Republic after changing of the regime in 1989 has gone through the process of the gradual privatization of the housing stock. Privatization, however, is slowly becoming a thing of the past, and so a question emerges: What factors have caused this development in recent years? To what extent have demographic and socioeconomic characteristics affected household's choice of the type of housing? Which of these characteristics has been statistically the most significant?

Our research relies on the following assumptions or hypotheses: (H1) - "Home ownership is preferred in households where the household head has a higher than basic education and is married. Rented housing is preferred by households with a lower income and that are "incomplete", specifically, divorced persons with children."

The second part of the analysis is based on the assumption that the same factors, which have an impact on tenure choice, also affect the expenditure share, which a household spends on housing (H2). That is why we study the same groups of factors as in the case of the probit model. This time we wish to establish whether the influence of a factor is significant (the appropriate coefficient is statistically greatly different from zero) and whether this influence is the same in the renting and ownership sectors. Then the differing values of the coefficient can point to the regions where the behaviour of renters and owners differs and where these is some space for potential interference from the outside or for the formulation of public policy.

\section{Method}

In order to analyse tenure choice we have applied an econometric model in accordance with the most frequent approaches. The model relies on a form of regression logit model (e.g. Bazyl, 2009; Ulker, 2008). This approach allows us (using the so-called odds ratios) to capture the individual influences of each set of potential factors that may affect tenure choice. The model enables to calculate the conditional probability of the choice of a particular type of housing depending on a given factor, provided that the values of other factors are constant. In this paper we have used a probit model, which has the following formula (Wooldridge, 2006):

$$
\log \frac{\pi}{1-\pi}=\beta_{0}+\beta_{1} X_{1}+\cdots+\beta_{k} X_{k}
$$

where $\pi=$ Probability of homeownership for a given value of $\mathrm{x}$ and takes the form of normal cumulative distribution function:

$$
\begin{aligned}
& \pi=\phi(\mathrm{z})=\int_{-\infty}^{\mathrm{z}} \frac{1}{\sqrt{2 \pi}} \mathrm{e}^{-\frac{\mathrm{u}^{2}}{2}} \mathrm{du} \\
& \mathrm{xk}=\text { Explanatory variables (see below) }
\end{aligned}
$$

$\beta \mathrm{k} \quad$ Coefficients estimated by the probit model.

The values of the coefficients $\beta \mathrm{k}$ express the effect of each factor on the tenure choice and at the same time show its direction. We refer to homeownership as the default choice, because the values of the coefficients $\beta \mathrm{k}$ are related to this option. Positive values of the coefficient $\beta \mathrm{k}$ therefore indicate that higher values of factor $\mathrm{xk}$ increase the likelihood of rental. On the other hand, negative values indicate that there is a greater likelihood of choosing home ownership in case of high values of factor xk. Then for those factors with a dichotomous nature (most often Yes/No), lower values of the factor mean 'No' and its higher values 'Yes'.

The regression model has also been applied to the second part of our analysis. The model serves to quantify the relationship between household composition and share of housing expenditure of the total household 
expenditures. The model considers this relation separately for owners (o) and renters (r).

Therefore, the econometric model has the form of two regression equations (Ulker, 2008):

For owners:

$$
\mathrm{w}_{\mathrm{o}, \mathrm{i}}=\alpha_{\mathrm{o}}+\beta_{\mathrm{o} 1} \ln \mathrm{M}_{\mathrm{o}, \mathrm{i}}+\beta_{\mathrm{o} 1}\left(\ln \mathrm{M}_{\mathrm{o}, \mathrm{i}}\right)^{2}+\gamma_{\mathrm{o}} \ln \mathrm{n}_{\mathrm{o}, \mathrm{i}}+\sum_{\mathrm{k}=1}^{\mathrm{k}-1} \eta_{\mathrm{o}, \mathrm{i}, \mathrm{k}} \frac{\eta_{\mathrm{o}, \mathrm{i}, \mathrm{k}}}{\eta_{\mathrm{o}, \mathrm{i}}}+\zeta_{\mathrm{o}} v_{\mathrm{o}, \mathrm{i}}+\mathrm{e}_{\mathrm{o}, \mathrm{i}}
$$

For renters:

$$
\mathrm{w}_{\mathrm{r}, \mathrm{i}}=\alpha_{\mathrm{r}}+\beta_{\mathrm{r} 1} \ln \mathrm{M}_{\mathrm{r}, \mathrm{i}}+\beta_{\mathrm{r} 1}\left(\ln \mathrm{M}_{\mathrm{r}, \mathrm{i}}\right)^{2}+\gamma_{\mathrm{r}} \ln \mathrm{n}_{\mathrm{r}, \mathrm{i}}+\sum_{\mathrm{k}=1}^{\mathrm{k}-1} \eta_{\mathrm{r}, \mathrm{i}, \mathrm{k}} \frac{\eta_{\mathrm{r}, \mathrm{i}, \mathrm{k}}}{\eta_{\mathrm{r}, \mathrm{i}}}+\zeta_{\mathrm{r}} \nu_{\mathrm{r}, \mathrm{i}}+\mathrm{e}_{\mathrm{r}, \mathrm{i}}
$$

In the model wo,i (wr,i) denotes the shares of housing expenditures of the owners (renters) in the total net household income Mo,i (Mr,i). Shares nk/nk, refer to the share of individual age groups of males and females in a given household. While parameter $\gamma$ captures the influence of household size on the housing expenditure share, parameter $\eta \mathrm{k}$ indicates the influence of gender and age composition of the household. Coefficient $\zeta$ captures the relationship between the share spent on housing and the vector of demographic and socio-economic variables (detailed composition of the vector is shown in Table 3).

The analyses included in this paper are based on the data pertaining to Czech households collected by the CSO (The Czech Statistical Office). The data were collected under sample surveys of income and living conditions of households between 2005 and 2010, under the Living Conditions Programme (called hereinafter the "EU-SILC"). This data set contains information on the social structure of households, their incomes and expenditures. The dates relate to the date of the investigation, i.e. the defined date in the spring of that year, only incomes are listed for the previous year. In order to convert the sample of households to the entire Czech Republic the coefficient of the "PKOEF" is used, which expresses the weighting of each surveyed household.

In the data sets, households are divided into five groups according to the form of ownership. For the purposes of our analysis, however, the relevant division is the category of home ownership or that of rented housing. Homeownership comprises of three different forms - living in an owned house, in a flat in personal ownership, and a flat in cooperative ownership. Lease and rental of the whole flat fall into the category of rented housing.

After calculations for the entire population of the CR it was ascertained that the percentage of homeownership significantly exceeds the percentage of rented housing and keeps increasing over time. The ownership percentage grew from $73.6 \%$ in 2005 to $80.6 \%$ in 2011 (see table 1).

The structure according to this indicator (after calculations for the entire population of the $\mathrm{CR}$ ) is as follows:

Table 1 . Household by tenure status

\begin{tabular}{lcccccccc}
\hline & 2005 & 2006 & 2007 & 2008 & 2009 & 2010 & & 2011 \\
& $\%$ & $\%$ & $\%$ & $\%$ & $\%$ & $\%$ & & $\%$ \\
\hline Owner-occupied & 73.6 & 74.1 & 74.9 & 76.0 & 76.8 & 79.1 & 3255087 & 80.6 \\
Tenant & 26.4 & 25.9 & 25.1 & 24.0 & 23.2 & 20.9 & 781341 & 19.4 \\
Total & 100.0 & 100.0 & 100.0 & 100.0 & 100.0 & 100.0 & 4036428 & 100.0 \\
\hline
\end{tabular}

Source: Authors, SILC database 2005-2011

In line with the above hypotheses, we focused on the examination of the impact of the demographic and socioeconomic characteristics of the households on tenure choice.

To some extent, the range of potential factors is determined by the used data source. Potential factors mostly comprise variables monitored within SILC survey (i.e. our source of data), or variables that can be derived from monitored variables.

In accordance with the proposed hypotheses we have concentrated on the household heads - their age, gender and marital status and also on the household from the perspective of its economic status, disposable income or number and age of children.

Since we believe that the factors influencing tenure choice are similarly projected into the structure of housing costs, we base our analysis on the same range of variables.

In examining the factors influencing tenure choice we use the vector of variables shown in Table 2. The table also provides average values of individual factors in households living in their own home (flat or house) and households living in rented housing in 2011. The variables with greatest differences can be seen as potential factors influencing tenure choice. 
Table 2. Summary statistics by tenure status (explanatory variables), 2011

\begin{tabular}{lcccccc}
\hline & \multicolumn{2}{c}{ Owners } & \multicolumn{2}{c}{ Renters } & \multicolumn{2}{c}{ Total } \\
Type of ownership & Mean & SD & Mean & SD & Mean & SD \\
\hline Household size (number of persons) & 2.567 & 1.222 & 2.301 & 1.295 & 2.515 & 1.241 \\
Number of economically active persons & 1.153 & 0.970 & 0.987 & 0.888 & 1.121 & 0.957 \\
Number of self-employed & 0.204 & 0.470 & 0.154 & 0.411 & 0.195 & 0.459 \\
Age of household head & 53.194 & 15.525 & 48.256 & 17.377 & 52.238 & 16.020 \\
Gender of household head (1=male & & & & & & \\
2=female) & 1.208 & 0.406 & 1.316 & 0.465 & 1.229 & 0.420 \\
Education in the household (1=both primary & & & & & & \\
school, 0-higher) & 0.065 & 0.247 & 0.113 & 0.317 & 0.075 & 0.263 \\
Household head is single* & 0.126 & 0.332 & 0.267 & 0.442 & 0.153 & 0.360 \\
Household head is married* & 0.615 & 0.487 & 0.388 & 0.487 & 0.571 & 0.495 \\
Household head is divorced* & 0.142 & 0.349 & 0.222 & 0.416 & 0.157 & 0.364 \\
Household with children* & 0.353 & 0.478 & 0.333 & 0.471 & 0.349 & 0.477 \\
Children under two years* & 0.079 & 0.270 & 0.090 & 0.287 & 0.081 & 0.273 \\
Fully employed household & 0.030 & 0.170 & 0.072 & 0.258 & 0.038 & 0.191 \\
At least one retiree & 0.276 & 0.447 & 0.233 & 0.423 & 0.267 & 0.443 \\
Household head works in public sector & 0.026 & 0.160 & 0.021 & 0.145 & 0.025 & 0.157 \\
Household resides in Prague* & 0.107 & 0.309 & 0.258 & 0.438 & 0.136 & 0.343 \\
Region** & 47.088 & 22.201 & 43.121 & 25.200 & 46.320 & 22.866 \\
Type of settlement*** & 2.984 & 0.969 & 2.465 & 1.028 & 2.883 & 1.002 \\
Total floor area per person & 38.889 & 22.751 & 31.571 & 17.206 & 37.473 & 21.979 \\
Household income (disposable) & 12.659 & 0.592 & 12.440 & 0.625 & 12.617 & 0.605 \\
\hline
\end{tabular}

*dichotomous variables take values 1 (Yes) / 0 (No)

**Region variable is take values from 11 (Prague) to 81 (North-Moravian Region)

***variable can take values: 1 (Prague), 2 (region), 3 (town), 4 (village)

$\mathrm{SD}$ - standard deviation

Source: Authors

Table 2 show thatlarger households (according to the number of its members) preferred homeownership to rented housing. At the same time these households were characterized by a higher number of economically active members or a higher number of the self-employed. As a rule, household head living in their own house or flat was a married male, average age around 53 with higher than basic education. Typically, home ownership was related to a larger total floor area per person but it must be noted that it ranged from 14 to $60 \mathrm{~m} 2$ per person. Households having at least one retired person tended to live in the homeownership sector. In contrast, households living in rented housing were headed by a woman with lower education and lower age (about 48 years). The woman was more often single or divorced than married. Households with no economically active member (and at least one unemployed) were more frequently found in rented housing. These households had considerably lower income in comparison with the households in the homeownership sector. However, there was no marked difference between home owners and renters as far as children are concerned (or babies up to two years of age). Virtually no impact on tenure choice was observed whether the household head was working in the public sector or not.

The above characteristic of households, based on average values of investigated factors, must be taken as tentative. The thing is that there could be a correlation between the analysed factors. In other words, differences in average values between rented and ownership housing can be caused by multiple factors, or an impact of other, latent variable. In order to distinguish a real impact of investigated factors on tenure choice it is necessary to use the econometric model, based on the probit estimation.

\section{Results and Discussion}

\subsection{Housing Tenure Choice}

Results of the regression analysis examining tenure choice determinants are summarized in Table 3. Marginal effects $\beta \mathrm{k}$ are computed not only for the year 2011 but they also cover a seven-year time span (2005-2011). This 
enables to assess trends of development of these effects.

Table 3. Probit Estimation results for housing tenure choice $(1=$ owner $)$

\begin{tabular}{|c|c|c|c|c|c|c|c|}
\hline \multirow[b]{2}{*}{ Factor $\left(x_{k}\right)$} & \multicolumn{7}{|c|}{ Marginal effect $\left(\boldsymbol{\beta}_{k}\right)^{* * *}$} \\
\hline & 2005 & 2006 & 2007 & 2008 & 2009 & 2010 & 2011 \\
\hline Constant & -6.291 & -5.865 & -5.180 & -5.185 & -6.556 & -6.528 & -6.468 \\
\hline Household size (number of persons) & -0.109 & -0.147 & -0.158 & -0.201 & -0.153 & -0.131 & -0.109 \\
\hline Number of economically active persons & -0.184 & -0.053 & -0.013 & -0.014 & -0.028 & -0.002 & -0.018 \\
\hline Number of self-employed & -0.097 & -0.180 & -0.176 & -0.134 & -0.094 & -0.070 & -0.035 \\
\hline Age of household head & -0.020 & -0.018 & -0.015 & -0.013 & -0.018 & -0.014 & -0.015 \\
\hline \multicolumn{8}{|l|}{ Gender of household head $(1=$ male } \\
\hline $2=$ female) & -0.068 & -0.011 & 0.028 & -0.030 & -0.051 & -0.011 & -0.027 \\
\hline $\begin{array}{l}\text { Education in the } \\
\text { primary school. }\end{array}$ & & & & & & & \\
\hline $\begin{array}{l}\text { primar } \\
\text { House }\end{array}$ & $\begin{array}{r}0.30 / \\
-0.375\end{array}$ & $\begin{array}{r}0.329 \\
-0.205\end{array}$ & $\begin{array}{r}0.210 \\
-0.122\end{array}$ & $\begin{array}{c}0.021 \\
-0.216\end{array}$ & $\begin{array}{l}0.00 / \\
-0.211\end{array}$ & $\begin{array}{l}0.293 \\
-0.088\end{array}$ & $\begin{array}{c}0.531 \\
-0.170\end{array}$ \\
\hline Household head is married" & -0.507 & -0.476 & -0.445 & -0.481 & -0.478 & -0.363 & -0.440 \\
\hline Household head is divorced ${ }^{*}$ & -0.166 & -0.056 & 0.034 & 0.014 & -0.063 & -0.008 & -0.084 \\
\hline Household with children ${ }^{*}$ & -0.180 & -0.021 & 0.016 & 0.008 & 0.021 & -0.094 & -0.195 \\
\hline Children under two years ${ }^{*}$ & -0.072 & -0.110 & -0.137 & -0.032 & -0.213 & -0.023 & 0.045 \\
\hline Fully unemployed household & -0.135 & 0.053 & 0.312 & 0.266 & 0.186 & 0.108 & -0.012 \\
\hline At least one retiree & -0.119 & 0.093 & 0.082 & -0.037 & 0.045 & -0.024 & -0.108 \\
\hline Household head works ir & -0.186 & -0.245 & -0.165 & -0.142 & -0.118 & -0.079 & -0.180 \\
\hline Household resides in Prague $^{*}$ & 0.329 & 0.311 & 0.345 & 0.319 & 0.176 & 0.141 & 0.336 \\
\hline Region & 0.005 & 0.007 & 0.006 & 0.007 & 0.004 & 0.002 & 0.003 \\
\hline Type of settlement** & -0.284 & -0.326 & -0.263 & -0.251 & -0.244 & -0.253 & -0.214 \\
\hline Total floor area per person & -0.023 & -0.024 & -0.025 & -0.024 & -0.024 & -0.022 & -0.021 \\
\hline Household income (disposable) & -0.297 & -0.286 & -0.264 & -0.261 & -0.346 & -0.373 & -0.378 \\
\hline
\end{tabular}

*dichotomous variables take values 1 (Yes) / 0 (No)

**variable can take values: 1 (Prague), 2 (region), 3 (town), 4 (village)

$* * *$ All values are statistical significant at $99 \%$ level (t-statistics are upon request by authors) excluded the coefficient market $n$

Source: Authors.

As expected, one of the most significant factors affecting the choice of type of housing in 2011 (as in other years) was the net disposable income of households $(\beta 2011=-0,378)$. Higher-income households tend to prefer homeownership to renting. The importance of this factor was growing over the covered period. The second strongest factor was the marital status of the household head. If the household head was married, the odds of choosing homeownership increased. The analogous assumption, i.e. that single or divorced persons would more likely prefer rented housing, was not confirmed. On the contrary, the singles were more likely to choose homeownership even if the strength of this factor was far weaker. Our findings showed that Prague households were more likely to choose rented housing $(\beta 2011=0,336)$. This fact can be linked with a high proportion of rented flats as compared with privately owned flats (or houses) in the capital city and so renting is a much faster and simpler way to acquire a new home there. Prague is also a university city, where many students and mainly graduates obviously prefer renting.

Among other strong (and statistically significant) factors, affecting tenure choice in 2011, was education of household members, household size and type of settlement, where the households resides (or household size). Rented housing was chosen with high probability by the households with a lower number of persons $(\beta 2011=-0,109)$, lower education of the head $(\beta 2011=0,351)$ or residence in a smaller town $(\beta 2011=-0,214)$. So the results corroborate the assumption that homeownership is affordable only for higher-income households, which usually corresponds to higher education. This housing type is preferred by families (not individuals), i.e. a higher number of persons per household, and also by households, whose members work, since it is necessary to make regular mortgage payments (i.e. the past significance of the number of economically active persons grew much weaker in 2011). For the first time children within a household became significant towards choosing 
homeownership in 2011. The influence of other factors, i.e. the number of self-employed, age or gender of the household head and the total floor area per person was not established.

By contrast, a sharp decline in the significance of economically active persons per household as a determining factor for tenure choice was observed throughout the period. While in 2005 a higher number of economically active persons markedly increased the odds of homeownership choice, $(\beta 2005=-0,184)$, by 2011 this factor nearly lost its significance $(\beta 2011=-0,018)$. An impact of the number of the self-employed per household, single or divorced persons, children, retired persons or fully unemployed persons is rather variable and hence uncertain over the long term.

Table 3 also indicates the development trends of the individual factors in tenure choice over the period 2005-2011. Throughout this period the following factors had a decisive effect on tenure choice: income of the household; education of its members; whether the head of the household was married or not. If the head of the household was married, the members of the household had a higher than basic education and a higher income, it implies the choice of homeownership. Our results in this respect correspond to the results of similar foreign studies. Ulker (2008) in his article showed that there was a highly significant influence of socio-economic characteristics, such as income and education on the tenure choice of households in the USA. Both Ulker and Bazyl (2009) confirmed a decisive impact of marriage on tenure choice of households throughout all monitored European countries.

\subsection{Housing Expenditures}

Factors influencing tenure choice have also been applied to the second part of our analysis, which discusses housing expenditures of households. Our goal is to evaluate, in accordance with Ulker's assumption (2008), whether households choose a certain type of housing tenure to optimize their housing-related expenditures. If so, we would like to establish to what degree. We seek answers to the question whether the factors, which influenced tenure choice of households, will be of the same significance in relation to their housing expenditures (or to their share in total expenditures).

Based on the above regression model (2) and (3), we examine the strength with which different coefficients affect the level of housing expenditures in households of owners versus households of renters. Unlike earlier studies, we observe development trends of monitored factors during 2005-2011, as in the case of tenure choice.

Table 4 summarises the results of regression analysis, and our hypothesis is only partly confirmed. Disposable household income influences not only the tenure choice itself but also the share of housing expenditure. This impact is more marked in renters $(\beta \mathrm{r} 2011=-4.115$ as compared with $\beta 02011=-3.047)$. Another significant factor in this context is the number of persons per household. Even here the factor has a stronger impact in the rented housing sector, where the housing share grows substantially with an increasing number of persons $\left(\gamma_{0} 2011=0.228\right)$. Differences between owners and renters are found in Prague households as well. While Prague residence is reflected rather neutrally in owners, or even slightly decreases their housing expenditures share, it is just opposite in the case of renters. Residence in Prague automatically raises the housing expenditures share ( $\zeta$ r2011=0.156). It is interesting that the influence of living in Prague on housing expenditures share has increased over the period covered (the growth began around 2008, that is with the onset of rent deregulation).

As evidenced by the results, the demographic composition of households affected the share of expenditures much more in the rented housing sector than in the homeownership sector. However, a more significant trend could not be determined. But surprisingly, a higher proportion of children under 10 years significantly reduced household housing expenditures share $(\eta 2009=-0.171)$.

The last important difference between home-owners and renters can be detected in the case of a type of settlement. While the size of settlement had a relatively small influence on housing expenditures share for owners ( $\zeta 2011=-0.020)$, renters were more strongly affected by the size of place they lived in $\zeta 2011=-0.049$ ). This means that in rented housing sector the share increases with the increase of municipality size.

As in tenure choice, age and gender of the household head were completely irrelevant for determining the housing expenditure share. It can also be stated that Czech households in both sectors adapt their floor area to the number of persons living in the dwelling. Thus, the relationship between tenure choice and housing expenditures share is confirmed. In accordance with our findings, households mostly take into account their future payments while choosing their home. The most interesting finding is a relatively small importance of marriage for the share of housing expenditures, which was similar in both sectors (renters vs. owners). If marriage is one of the most significant reasons for households to select homeownership and if marriage does not influence housing expenditure share of owners, we can deduce that homeownership choice is motivated by the social status rather 
than the economy. For particular type of households (married, with children) to live in homeownership is more important than to live in such type of tenure, which optimises the cost of living.

Table 4. Impact of factors on the share of housing expenditures

\begin{tabular}{|c|c|c|c|c|c|c|c|c|}
\hline & \multicolumn{4}{|c|}{ Owners } & \multicolumn{4}{|c|}{ Renters } \\
\hline & 2005 & 2007 & 2009 & 2011 & 2005 & 2007 & 2009 & 2011 \\
\hline (Constant) & $14.942^{* *}$ & $15.877^{* *}$ & $22.136^{* *}$ & $20.877^{* *}$ & $18.852^{* *}$ & $26.433^{* *}$ & $54.274^{* *}$ & $27.932^{* *}$ \\
\hline Net household income $(\ln M)$ & $-2.199^{* *}$ & $-2.308^{* *}$ & $-3.234^{* *}$ & $-3.047^{* *}$ & $-2.815^{* *}$ & $-4.006^{* *}$ & $-8.289^{* *}$ & $-4.115^{* *}$ \\
\hline $\begin{array}{l}\text { Second power of log income } \\
(\ln M)^{2}\end{array}$ & $0.081^{* *}$ & $0.084^{* *}$ & $0.118^{* *}$ & $0.112^{* *}$ & $0.105^{* *}$ & $0.152^{* *}$ & $0.315^{* *}$ & $0.151^{* *}$ \\
\hline $\begin{array}{l}\text { Number of persons per household } \\
(\ln n)\end{array}$ & $0.064^{* *}$ & $0.075^{* *}$ & $0.090^{* *}$ & $0.105^{* *}$ & $0.131^{* *}$ & $0.154^{* *}$ & $0.317^{* *}$ & $0.228^{* *}$ \\
\hline $\begin{array}{l}\text { Number of economically active } \\
\text { persons }\end{array}$ & $0.002^{* *}$ & $-0.001^{* *}$ & $-0.002^{* *}$ & $-0.009^{* *}$ & $-0.015^{* *}$ & $-0.021^{* *}$ & $0.004^{* *}$ & $0.008^{* *}$ \\
\hline Number of self-employed & $0.006^{* *}$ & $0.005^{* *}$ & $0.007^{* *}$ & $-0.002^{* *}$ & $0.033^{* *}$ & $0.003^{* *}$ & $-0.052^{* *}$ & $0.007^{* *}$ \\
\hline Proportion of men aged $0-10$ & $0.027^{* *}$ & -0.001 & $-0.021^{* *}$ & $-0.093^{* *}$ & $0.012^{* *}$ & $-0.027^{* *}$ & $-0.171^{* *}$ & $-0.041^{* *}$ \\
\hline Proportion of men aged 11-17 & $0.060^{* *}$ & $0.027^{* *}$ & $0.001^{* *}$ & $-0.039^{* *}$ & $0.031^{* *}$ & $-0.058^{* *}$ & $-0.071^{* *}$ & $-0.044^{* *}$ \\
\hline Proportion of men aged $18-29$ & $0.049^{* *}$ & $0.009^{* *}$ & $0.023^{* *}$ & -0.001 & $0.127^{* *}$ & $-0.005^{* *}$ & $0.093^{* *}$ & $0.026^{* *}$ \\
\hline Proportion of men aged 30-59 & $0.051^{* *}$ & $0.008^{* *}$ & $0.004^{* *}$ & $-0.007^{* *}$ & $0.134^{* *}$ & $0.041^{* *}$ & $0.122^{* *}$ & $0.052^{* *}$ \\
\hline Proportion of men aged $60+$ & $0.058^{* *}$ & $0.007^{* *}$ & $0.018^{* *}$ & $0.002^{* *}$ & $0.130^{* *}$ & 0.001 & $0.069^{* *}$ & $0.074^{* *}$ \\
\hline Proporti & $0.044^{* *}$ & $0.003^{* *}$ & $-0.013^{* *}$ & $-0.098^{* *}$ & $0.152^{* *}$ & $-0.070^{* *}$ & $-0.046^{* *}$ & $-0.007^{* *}$ \\
\hline Proportion of women aged 11-17 & $0.063^{* *}$ & $0.016^{* *}$ & $0.006^{* *}$ & $-0.057^{* *}$ & $0.030^{* *}$ & $0.047^{* *}$ & $-0.041^{* *}$ & $0.030^{* *}$ \\
\hline Proportion of women aged 18-29 & $0.052^{* *}$ & $0.024^{* *}$ & $0.036^{* *}$ & $-0.008^{* *}$ & $0.096^{* *}$ & $0.006^{* *}$ & $0.095^{* *}$ & $0.113^{* *}$ \\
\hline Proportion of women aged 30-59 & $0.076^{* *}$ & $0.007^{* *}$ & $0.037^{* *}$ & $0.036^{* *}$ & $0.096^{* *}$ & $-0.026^{* *}$ & $0.071^{* *}$ & $0.097^{* *}$ \\
\hline Prop & $0.056^{* *}$ & $0.010^{* *}$ & $0.021^{* *}$ & $0.009^{* *}$ & $0.103^{* *}$ & $-0.015^{* *}$ & $0.074^{* *}$ & $0.030^{* *}$ \\
\hline Household head married & $0.036^{* *}$ & $0.016^{* *}$ & $0.024^{* *}$ & $0.012^{* *}$ & $0.044^{* *}$ & $0.039^{* *}$ & $0.009^{* *}$ & $0.031^{* *}$ \\
\hline Household head single & $0.018^{* *}$ & $-0.014^{* *}$ & $-0.011^{* *}$ & $-0.002^{* *}$ & $0.048^{* *}$ & $0.032^{* *}$ & $0.008^{* *}$ & 0.001 \\
\hline Household head divorced & $0.011^{* *}$ & $0.012^{* *}$ & $0.001^{* *}$ & $0.001^{* *}$ & $0.002^{* *}$ & $0.010^{* *}$ & $0.008^{* *}$ & $0.019^{* *}$ \\
\hline Fully & $0.035^{* *}$ & $-0.003^{* *}$ & $-0.096^{* *}$ & $-0.032^{* *}$ & $-0.046^{* *}$ & $-0.049^{* *}$ & $-0.090^{* *}$ & $0.096^{* *}$ \\
\hline Household education & $-0.045^{* *}$ & $-0.033^{* *}$ & $-0.039^{* *}$ & $-0.016^{* *}$ & $-0.027^{* *}$ & $-0.051^{* *}$ & $-0.119^{* *}$ & 0.000 \\
\hline At least one retired person & $-0.027^{* *}$ & $-0.028^{* *}$ & $-0.065^{* *}$ & $-0.031^{* *}$ & $-0.027^{* *}$ & $-0.069^{* *}$ & $-0.070^{* *}$ & $-0.013^{* *}$ \\
\hline tor & $0.002^{* *}$ & $0.011^{* *}$ & $0.007^{* *}$ & $0.001^{* *}$ & $-0.008^{* *}$ & $-0.009^{* *}$ & $0.034^{* *}$ & $-0.025^{* *}$ \\
\hline des in Prague & $-0.022^{* *}$ & $-0.014^{* *}$ & $-0.012^{* *}$ & $-0.009^{* *}$ & $-0.022^{* *}$ & $-0.013^{* *}$ & $0.053^{* *}$ & $0.028^{* *}$ \\
\hline Region & $0.000^{* *}$ & $0.000^{* *}$ & $0.000^{* *}$ & $0.000^{* *}$ & $-0.001^{* *}$ & $0.000^{* *}$ & $0.000^{* *}$ & $-0.001^{* *}$ \\
\hline Type of settlement** & $-0.029^{* *}$ & $-0.025^{* *}$ & $-0.025^{* *}$ & $-0.020^{* *}$ & $-0.034^{* *}$ & $-0.022^{* *}$ & $-0.031^{* *}$ & $-0.049^{* *}$ \\
\hline Total floor area per person & $0.001^{* *}$ & $0.001^{* *}$ & $0.000^{* *}$ & $0.000^{* *}$ & $0.002^{* *}$ & $0.003^{* *}$ & $0.005^{* *}$ & $0.005^{* *}$ \\
\hline Age of household head & $0.000^{* *}$ & $0.000^{* *}$ & $0.000^{* *}$ & $-0.001^{* *}$ & $-0.032^{* *}$ & $-0.001^{* *}$ & $-0.001^{* *}$ & $0.000^{* *}$ \\
\hline Gender of household head & $0.006^{* *}$ & $-0.001^{* *}$ & $-0.001^{*}$ & $-0.005^{* *}$ & $0.033^{* *}$ & $0.029^{* *}$ & $-0.003^{* *}$ & $0.015^{* *}$ \\
\hline
\end{tabular}

Source: Authors.

\section{Conclusion}

As in other countries, many factors influence the decisions of Czech households to live in rented housing or in their own home. Although the motive of homeownership as a long-term investment cannot be neglected, most studies report that the greatest influence is exercised by demographic and socio-economic composition of 
household. Our results corroborate this assumption to a considerable degree. During 2005-2011 tenure choice was particularly influenced by household income, education of its members, and marital status of the household head (married, single or divorced), residence in Prague or elsewhere. By contrast, gender or age of the household head, children or retired persons living in the household proved to be insignificant. The results greatly support our hypotheses proposed at the beginning of our research. We have succeeded in confirming the hypothesis that higher education of household members (including the household head) and marriage of the household head are more likely to lead to homeownership. However, the second part of our hypothesis has only partly been supported. It has been confirmed that the lower the income of a household indicates that the household prefers rented housing. On the other hand, incomplete households (e.g. divorced persons with children) have not been proved to prefer renting.

When we search for motives behind the decisions it appears that one of the major reasons for choosing renting or owning is the attempt to optimize the share of housing expenditures in total expenditure of households. Therefore it might be assumed that some of the above determinants of tenure choice affect the share of housing expenditure.

Our results have confirmed this assumption to a considerable degree. Again, income is crucial in this case, and this impact is far more important in renting than in home- ownership. Of similar importance is the number of persons per household which is again more significant in renting. Governmental housing policy should be aware of the important fact that a higher housing share has been proved for renters in Prague. In contrast, age, gender, or marital status of the household head, have not been proved to exert influence in any sector. Generally speaking, demographic and socio-economic factors have a more significant impact on housing expenditure share in the renting sector than in the ownership sector.

Of course, the interpretation of the submitted results must be treated with caution. The EU-SILC is a sample survey, in which 11,249 households were examined out of the total of 4,018,288 in the year 2011. The source data are only statistical estimates, which are burdened with an unspecific error. We believe, however, that despite these limitations the results presented are relevant and conclusions can be drawn from them.

The conclusions from our analysis can be helpful mainly for the housing policy-makers. There has been a noticeable effort recently to target governmental housing subsidies more precisely in the Czech Republic. The general aims as well as the purpose of particular subsidies have gradually been specified better. At present the target group of subsidies is defined more precisely and housing subsidies are aimed at the disadvantaged as for the access to housing, particularly because of their income, age, ethnicity, or economic status. The results of our calculations corroborate that some of these characteristics pre-determine some households to renting their homes and so they prove that the support of the state should rather be directed to rental housing if it is to achieve its set goal.

The presented analysis is a step forward but still further research is needed. From the perspective of the public housing-related policy it is naturally very interesting to link the issues of tenure choice with those of housing expenditures. If we could prove that there is a group of people with a clearly different level of housing-related costs, it would be, undoubtedly, important information for the setting or the targeting of social policy.

\section{Acknowledgements}

The preparation of this paper was supported by the GA CR project P403/12/0366: Identification and evaluation of region specific factors determining outcomes of reforms based on NPM- the case of CEE.

\section{References}

Andersen, H. S. (2009). Explanation for Preferences in Denmark for Surroundings and Location of the Home. Paper for ENHR conference, Prague.

Artle, R., \& Varaiya, P. (1978). Life Cycle Consumption and Homeownership. Journal of Economic Theory, 18(1), 38-58. http://dx.doi.org/10.1016/0022-0531(78)90041-8

Bazyl, M. (2009). Factors Influencing Tenure Choice in European Countries. Warsaw School of Economics. Working paper No. 1-09.

Boehm, T. P. (1981). Tenure Choice and Expected Mobility: A Synthesis. Journal of Urban Economics, 10(3), 375-389. http://dx.doi.org/10.1016/0094-1190(81)90008-5

Boehm, T. P. (1982). A Hierarchical Model of Housing Choice. Urban Studies, 19(1), 17-31. http://dx.doi.org/10.1080/00420988220080021 
Bramley, G. (2011). Housing Mobility and Tenure Choice with Varying Constraints and Rationing: A Model for English Regions Built from Micro Household Data. Paper submitted to ENHR Conference, Toulouse, July 2011.

Burgess, S. L. (1982). Determinants of Homeownership: A Comparison of Single Female and Single Male Headed Households. Housing and Society, 9(2), 87-94.

COMMISSION REGULATION (EC) No 1983/2003, implementing Regulation (EC) No 1177/2003 of the European Parliament and of the Council concerning Community statistics on income and living conditions (EU-SILC) as regards the list of target primary variables.

Coolen, H., Boelhouwer, P., \& Van driel, K. (2002). Values and goals as determinants of intended tenure choice. Journal of Housing and the Built Environment, 17, 215-236. http://dx.doi.org/10.1023/A:1020212400551

Fisher, L. M., \& Jaffe, A. J. (2003). Determinants of International Home Ownership Rates. Housing Finance International. Retrieved from http://www.housingfinance.org/uploads/Publicationsmanager/0309_Det.pdf

Jahoda, R., \& Godarová, J. (2013). Microsimulation of the Mortage Interest Deduction. The Czech Case. Proceedings of the 17th International Conference: Current Trends in Public Sector Research. Brno: Masarykova univerzita, 2013. s. 246-254

Jahoda, R., \& Špalková, D. (2012). Housing-induced Poverty and Rent Deregulation: A Case Study of the Czech Republic. Ekonomický časopis / Journal of Economics, 60(2), 146-168.

Henderson, J. V., \& Ioannides, Y. M. (1983). A Model of Housing Tenure Choice. The American Economic Review, 73(1), 98-113.

Kan, K. (2000). Dynamic Modelling of Housing Tenure Choice. Journal of Urban Economics, 48(1), 46-69. http://dx.doi.org/10.1006/juec.1999.2152

Krumm, R. J. (1984). Household Tenure Choice and Migration. Journal of Urban Economics, 16(3), 259-271. http://dx.doi.org/10.1016/0094-1190(84)90027-5

Lux, M., \& Sunega, P. (2012). Labour Mobility and Housing: The Impact of Housing Tenure and Housing Affordability on Labour Migration in the Czech Republic. Urban Studies, 49(3), 599-614. http://dx.doi.org/10.1177/0042098011405693

Tsharakyan, A., \& Zemčík, P. (2011). Rent Deregulation, Tenure Choice, and Real Estate Price Expectations. CERGE-EI Working Papers wp430, The Center for Economic Research and Graduate Education Economic Institute, Prague.

Turner, M. A., \& O’Neal, K. (1986). Household Tenure Choice. Review of the Empirical Literature. The Urban Institute, Washington.

Ulker, A. (2008). Household Composition and Housing Expenditures in Rental-Occupied and Owner-Occupied Markets. Family and Consumer Sciences Research Journal, 36(3), 189-207. http://dx.doi.org/10.1177/1077727X07311686

Wooldridge, J. M. (2006). Introductory Econometrics: A Modern Approach (3rd ed., p. 890). Mason: Thomson/South-Western.

\section{Copyrights}

Copyright for this article is retained by the author(s), with first publication rights granted to the journal.

This is an open-access article distributed under the terms and conditions of the Creative Commons Attribution license (http://creativecommons.org/licenses/by/3.0/). 